\title{
Distribution of rRNA genes in breeds of domestic pig studied by non-radioactive in situ hybridization and selective silver-staining
}

\author{
CHM Mellink ${ }^{1}$, AA Bosma ${ }^{1}$, NA de $\operatorname{Haan}^{1}$, J Wiegant ${ }^{2}$ \\ 1 Faculty of Veterinary Medicine, Utrecht University, \\ Department of Cell Biology and Histology, PO Box 80.157, 3508 TD Utrecht; \\ 2 Faculty of Medicine, Leiden University, Department of Cytochemistry and Cytometry, \\ Leiden, The Netherlands
}

(Proceedings of the 9th European Colloquium on Cytogenetics of Domestic Animals; Toulouse--Auzeville, 10-13 July 1990)

pig breeds / chromosomes / in situ hybridization / rRNA genes / nucleolar organizer regions (NORs)

\section{INTRODUCTION}

Radioactive in situ hybridization in the domestic pig has revealed that the rRNA genes are located either in the secondary constriction of chromosome 10 only (Miyake et al, 1988), or in the secondary constrictions of chromosomes 10 and 8 (Toga-Piquet et al, 1984; Vagner-Capodano et al, 1984).

Silver $(\mathrm{Ag})$ staining has been proven to be a reliable technique for demonstrating nucleolar organizer regions (NORs) on chromosomes and to be indicative of active ribosomal RNA synthesis (Howell, 1982).

Variations in number and size of Ag-NORs have been observed in several species, including the pig (Czaker and Mayr, 1980, 1982; Mayr and Schleger, 1981; Vischnevskaya and Vsevodolov, 1986). According to these authors, silver deposits are largest on chromosomes 10, while they are smaller or absent on chromosomes 8.

In the present study, chromosomes of 6 different pig breeds were examined for: 1) the localization of the rDNA, using non-radioactive in situ hybridization, 2) Ag-NOR staining patterns, and 3) polymorphism for the amount of rDNA. 


\section{MATERIALS AND METHODS}

Blood samples were collected from 40 animals belonging to the following breeds: Dutch Landrace, Yorkshire, Norwegian Landrace, Finnish Landrace, Piétrain and Meishan. Cultures of phytohemagglutinin (PHA)-stimulated peripheral blood lymphocytes were set up, and chromosome preparations made, following standard procedures.

In situ hybridization was carried out in 11 pigs, using a biotinylated $5.2 \mathrm{~kb}$ $B g l \mathrm{II}-E c o$ RI human rDNA probe (Wachtler et al, 1989). Silver-staining of NORs was performed in all 40 pigs, following the $\mathrm{Ag}$ - $\mathrm{AS}$ (ammoniacal-silver) technique of Goodpasture and Bloom (1975).

An attempt was made to quantify the amount of silver deposited on the NORs by means of image analysis. The area of the silver deposit was divided by the length of the chromosome.

\section{RESULTS AND DISCUSSION}

In situ hybridization revealed that the secondary constrictions of both chromosomes 10 and both chromosomes 8 were the sites of location of the rRNA genes in the breeds examined (table I) with the exception of the Dutch Landrace pig and one Meishan pig, which also had cells exhibiting only 3 fluorescent signals. However, in both cases, these exceptions can be explained by difficulties in detection due to the presence of a very small signal on one chromosome 8 . In general, the size and intensity of the signals varied between chromosomes 10 and 8 , between the two homologues of pair 10 and between the two homologues of pair 8 . In most animals, the signals on chromosome 10 were largest, but in some animals (the Yorkshire pig and one Piétrain pig) chromosome 8 had a stronger signal. These observations suggest that differences exist in the amounts of rDNA present at the 4 nucleolar organizer regions.

Table I. Numbers and cellular distribution of in situ hybridization signals in 11 pigs of 6 breeds.

\begin{tabular}{llccc}
\hline \multicolumn{1}{c}{ Breed } & $n$ & $\begin{array}{c}10 / 10 \\
-/\end{array}$ & $\begin{array}{c}10 / 10 \\
8 /-\end{array}$ & $\begin{array}{c}10 / 10 \\
8 / 8\end{array}$ \\
\hline Dutch Landrace & 45 & 0 & 21 & 24 \\
Yorkshire & 20 & 0 & 0 & 20 \\
Norwegian Landrace & 10 & 0 & 0 & 10 \\
Finnish Landrace & 20 & 0 & 1 & 19 \\
Piétrain & 20 & 0 & 0 & 20 \\
Piétrain & 20 & 0 & 1 & 19 \\
Meishan & 15 & 0 & 0 & 15 \\
Meishan & 15 & 0 & 5 & 10 \\
Meishan & 15 & 0 & 0 & 15 \\
Meishan & 20 & 0 & 0 & 20 \\
Meishan & 20 & 0 & 0 & 20 \\
\hline
\end{tabular}

$n=$ number of cells studied. 
Silver staining revealed either 2,3 or $4 \mathrm{Ag}$-NORs in the cells of the animals studied. The NORs of chromosomes 10 were consistently silver-positive, whereas the NORs of chromosomes 8 varied in staining. We concluded that the NORs of chromosomes 10 were transcriptionally active in all cells, whereas the NORs of chromosomes 8 were not or were active to a variable degree. Table II presents mean numbers of Ag-NORs for each breed. The lowest mean numbers were found in the Dutch, Norwegian and Finnish Landraces. Moderate mean numbers were observed in the Yorkshire and Piétrain breeds. An extremely high number of Ag-NORs was scored in the Meishan breed. The results of this study include higher mean numbers of Ag-NORs than have been found for certain other breeds: Austrian Landrace 2.17, Deutsch Edelschwein 2.24, Belgian Landrace 2.38 (Czaker and Mayr, 1982). However, Czaker and Mayr (1982), and Vischnevskaya and Vsevodolov (1986) found similar mean Ag-NOR values for the Piétrain breed (2.54), and for the Large White and Duroc breeds (2.53 and 2.75, respectively). The ranges given in table II demonstrate that, within the breeds investigated in this study (with the exception of the Meishan breed), considerable individual variability exists with regard to the $\mathrm{Ag}-\mathrm{NOR}$ number.

Table II. Mean numbers of Ag-NORs in 6 pig breeds.

\begin{tabular}{lrcc}
\hline \multicolumn{1}{c}{ Breed } & $n$ & Range & $X \pm S D$ \\
\hline Dutch Landrace & 10 & $2.04-3.04$ & $2.51 \pm 0.37$ \\
Yorkshire & 5 & $2.13-3.73$ & $2.77 \pm 0.73$ \\
Norwegian Landrace & 7 & $2.04-2.88$ & $2.32 \pm 0.32$ \\
Finnish Landrace & 7 & $2.00-3.12$ & $2.54 \pm 0.51$ \\
Piétrain & 6 & $2.20-4.00$ & $3.06 \pm 0.78$ \\
Meishan & 5 & $3.94-4.00$ & $3.97 \pm 0.03$ \\
\hline
\end{tabular}

$n=$ number of animals studied.

Apart from the variation in Ag-NOR number, variation in the amount of silver deposited was observed. In most cells, the largest amounts of silver were present on chromosomes 10. Chromosomes 8 usually showed much smaller Ag-NORs or no (detectable) silver deposit at all. Also, in some animals, consistent differences in Ag-NOR size between homologous chromosomes were observed. Figure 1 shows a metaphase spread with Ag-NORs on chromosomes 10 (distinct dimorphism) and 8 (slight dimorphism).

The results of quantification by image analysis of the amounts of silver deposited on the NORs of the 5 Meishan pigs are presented in figure 2. Some of these animals showed relatively little polymorphism for the amount of silver on their NORs, whereas the others showed a more marked polymorphism in this respect. Again, the Ag-NORs on chromosomes 10 were usually the largest. The metaphase spread shown in figure 1 came from the animal second from left in figure 2 . These quantification studies will be continued. 


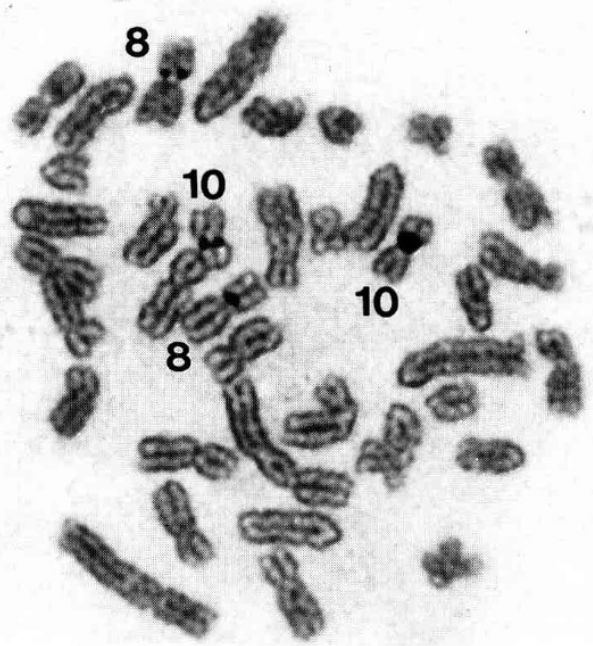

Fig 1. Silver-stained metaphase spread from a Meishan pig, showing polymorphism of the Ag-NORs.

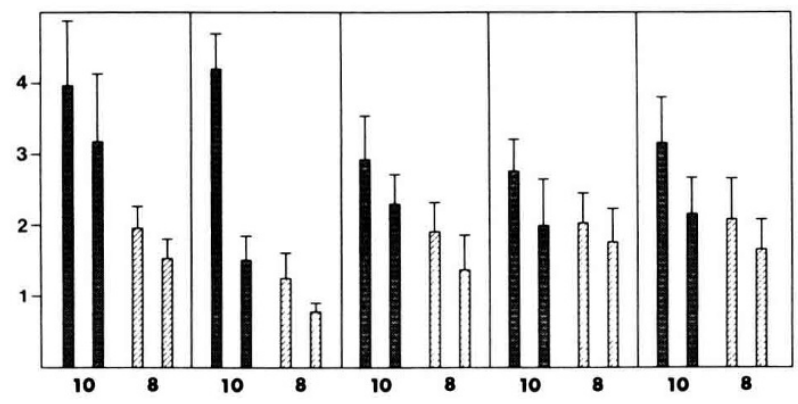

Fig 2. Histograms showing the relative size of the Ag-NORs in 5 Meishan pigs (mean values based on 5 cells).

\section{ACKNOWLEDGMENTS}

The authors wish to thank BV Cofok (Oosterhout, Gld, The Netherlands) and the Department of Animal Breeding of the Agricultural University at Wageningen (The Netherlands) for providing animals for blood sampling.

\section{REFERENCES}

Czaker R, Mayr B (1980) Detection of nucleolus organizer regions in the chromosomes of the domestic pig (Sus scrofa domestica L). Experientia 36, 1356-1357 
Czaker R, Mayr B (1982) Comparative studies on the polymorphism of nucleolus organizer regions (NORs) in four breeds of domestic pigs (Sus scrofa domestica L) with special emphasis on the development of breeds. Z Zool Syst Evolutions Forsch 20, 233-241 Goodpasture C, Bloom SE (1975) Visualization of nucleolar organizer regions in mammalian chromosomes using silver staining. Chromosoma 53, 37-50

Howell WM (1982) Selective staining of nucleolus organizer regions (NORs). In: The Cell Nucleus vol XI, (Bush H, Rothblum I, eds) Academic Press, New York, 89-142

Mayr B, Schleger W (1981) Cytogenetic investigations in Austrian bulls and boars. Zbl Vel Med A 28, 70-75

Miyake ML, O'Brien SJ, Kaneda Y (1988) Regional localization of rDNA genes on pig chromosome 10 by in situ hybridization. Jpn J Vet Sci 50, 341-345

Toga-Piquet C, Henderson AS, Grillo JM, Vagner-Capodano AM, Stahl A (1984) Localisation des gènes ribosomiques et activité nucléolaire dans les lymphocytes du porc (Sus scrofa domestica) stimulés par la phytohémagglutinine. CR Séances Acad Sci III 298, 383-386

Vagner-Capodano AM, Henderson AS, Lissitzky S, Stahl A (1984) The relationship between ribosomal genes and fibrillar centers in thyroid cells cultivated in vitro. Biol Cell 51, 11-22

Vischnevskaya SS, Vsevodolov EB (1986) Individual variability and inheritance of the number and size of the nucleolar organizer regions of the domestic pig chromosomes. Genetika 22, 690-698

Wachtler F, Hartung M, Devictor M, Wiegant J, Stahl A, Schwarzacher HG (1989) Ribosomal DNA is located and transcribed in the dense fibrillar component of human Sertoli cell nucleoli. Exp Cell Res 184, 61-71 